\title{
TIEMPOS DE CAMBIOS EN LAS ACTITUDES POLÍTICAS DE LOS VENEZOLANOS
}

\author{
Valia Pereira Almao*
}

\section{INTRODUCCIÓN}

Este trabajo tiene por finalidad examinar los rasgos fundamentales de las actitudes políticas de los venezolanos que han contribuido al ocaso del modelo político de conciliación de intereses que sustentó a la democracia en Venezuela hasta 1988, entre los cuales están el debilitamiento de las lealtades partidistas, el estilo de democracia interiorizado y las diferencias ideológicas y sociales respecto de la desigualdad social.

Desde 1983 el país viene atravesando por severos desequilibrios económicos que han venido deteriorando las finanzas públicas y el nivel de vida de la población, situación que se agravó en 1989 y desencadenó medidas de ajuste que resintieron la situación social y política del país. La base política consensual que garantizaba la gobernabilidad del país, apoyada principalmente por los partidos políticos tradicionales, Acción Democrática (AD) y el partido socialcristiano (COPEI), ha perdido la confianza de la población; y el Estado distributivo de base rentista petrolera ha mermado sus capacidades para reducir los conflictos sociales (Rey, 1991; Borges, 1992; Kornblit, 1996).

En 1993 y 1998 ganan respectivamente la Presidencia los líderes personales Rafael Caldera y el Jefe del golpe militar del 4 de febrero de 1992, Comandante Hugo Chávez (sobreseido por Caldera y retirado del ejército) en oposición a los partidos hegemónicos y se quiebra el bipartidismo (ADCOPEI). El voto parlamentario se dispersó entre varios partidos (Molina y Pérez, 1995: 79-81) y además del Movimiento Al Socialismo, MAS (tradicional partido minoritario centro izquierdista), emergen La Causa Radical (Causa R) y Convergencia Nacional en 1993, los cuales se convierten en minoritarios en 1998 (incluido Patria Para Todos, PPT, surgido de la división de La Causa $R$ en 1996) y surgen otros nuevos, el Movimiento V República (MVR, el partido de Chávez) con un discurso bolivariano de apelación popular, constituido, entre otros, por militares no activos que participaron en los intentos golpistas del 92 y el partido Proyecto Venezuela de centro-derecha.

La abstención electoral ha aumentado, 39,8\% en 1993 (Molina,1985; Molina y Pérez: 1996, Vaivads, 1994) y 36,2\% en 1998, con respecto a épocas anteriores (menor de $18 \%$ ). De 1973 a 1988 AD y COPEI concentraron aproximada- mente el $80 \%$ de los votos presidenciales y lograron gobernar con mayorías parlamentarias o alianzas de corta duración en un esquema bipartidista atenuado (Molina y Pérez, 1994:13). Pero ahora el multipartidismo es inestable porque todavía no se afianzan lealtades partidistas duraderas.

El apoyo electoral hacia AD y COPEI estuvo impulsado por lealtades partidistas consistentes, según señalan investigaciones anteriores: 1 - no se observaba una influencia clasista en las preferencias partidistas por AD y COPEI, eran partidos policlasistas, 2 - las diferencias demográficas e ideológicas de sus partidarios no resultaban significativas y 3 las diferencias regionales eran irrelevantes, eran partidos nacionales (Baloyra y Martz, 1979: 46-49; Torres, 1978: 12 17; Torres, 1980b: 16-17; Torres, 1982). La fuerte exposición y acomodamiento de los venezolanos al esquema de competitividad interpartidista se realizaba plenamente en la "fiesta electoral" (Torres, 1982: 39-40) estimulado por las políticas distributivas del Estado, el clientelismo partidista y las expectativas de bienestar y movilidad social.

Un efecto dramático de la crisis económica y de las ejecutorias ineficaces de los gobiernos nacionales ha sido el empobrecimiento de la población. Con base en el análisis de la distribución histórica del ingreso en Venezuela, se ha mostrado que los gobiernos democráticos entre 1958 y 1980 proporcionaron mejoras sociales y económicas que permitieron un claro ascenso de los ingresos entre los años 1962 y 1980 y que se empezó a revertir en 1983 (Crisp. et. al.,1996: 1415; F.A.C.E.S., 1982: 29). Durante la década de los 80 la inflación abatió los ingresos de los hogares y sobre todo los de las clases bajas cuyos ingresos medios se redujeron en 1988 hasta un tercio de sus ingresos reales en 1984 (Maxim Ross y Asociados, S.A., 1989: 17). Los datos del primer semestre de 1997 de la Encuesta de Hogares de la Oficina Central de Estadística e Informática de Venezuela (OCEI), revelan una gran inequidad, ya que el $41,98 \%$ de los hogares tiene ingresos mensuales menores a 80.000 bolívares (Bs.), lo que equivale a una situación de precaria subsistencia por cuanto que la canasta de consumo alimentario básico para una familia de seis personas se ubicaba para ese momento en 100.000

Investigadora del Instituto de Estudios Políticos y Derecho Público de la Universidad de Zulia, Maracaibo, Venezuela. 
Bs. mensuales; y el 48,13\% de los hogares apenas cubre sus necesidades básicas ya que sus ingresos están entre 80.000 y 300.000 Bs. al mes.

Las opiniones de los entrevistados en la Encuesta de Valores $1995^{1}$ respecto de la pobreza revelan su impacto, el $92 \%$ piensa que ahora hay mayor pobreza que hace 10 años, el $59,6 \%$ cree que la mayoría de los pobres del país no tiene el chance de salir de la pobreza y $79,9 \%$ dice que el gobierno hace muy poco por la gente pobre.

El recrudecimiento de la pobreza revela las limitaciones del estado proteccionista para garantizar los ideales de libertad y bienestar que acompañaron al proyecto democrático iniciado en 1958. La legitimidad política de ese modelo está en problemas y hay dificultades para mitigar el conflicto social, debido al decaimiento sostenido de los ingresos petroleros, el déficit fiscal (aproximadamente $8 \%$ del Producto Interno Bruto para 1998), el elevado costo de la deuda externa y la escasa habilidad del sistema para proveer soluciones (Crisp. et. al., 1996: 26).

A objeto de establecer los rasgos principales de las actitudes políticas sobre los cuales se asienta la democracia venezolana en la actualidad, el presente trabajo intenta examinar la consistencia de las lealtades partidistas, el estilo de democracia prevaleciente e indagar en las divisiones ideológicas y sociales respecto de la desigualdad social, haciendo uso del método estadístico para el análisis de encuestas y la comparación de datos provenientes de encuestas hechas en 1973, 1983, 1993 y 1995 con fines de investigación científica ${ }^{2}$.

\section{EL DEBILITAMIENTO DEL PARTIDISMO EN VENEZUELA}

La partidización de los venezolanos no se encuentra en la actualidad vinculada a las diferenciaciones típicas de los individuos en la sociedad (sexo, edad, ingreso y nivel de instrucción). Al hacer los cruces de variables respectivos con los datos provenientes de la Encuesta IEPDP93 se obtiene que son en su mayoría no significativos (Chi-cuadrado, $\mathrm{X}^{2}$ ) al 0.05 y sin asociación relevante. Sólo el cruce de identificación partidista y nivel de instrucción es significativo al 0.01 y sugiere que quienes tienen nivel de instrucción primaria o inferior son algo más partidizados que el resto y los de educación secundaria son un poco más independientes, pero el nivel de asociación Somers $₫ D_{\mathrm{yx}}$ es irrelevante $(0.03025)$ y no permite establecer una influencia cierta. Esos resultados son compatibles con otros trabajos de investigación realizados en Venezuela donde aquellas diferenciaciones sociales no aparecían vinculadas al partidismo, y se concluía que era la partidización familiar la que influenciaba la partidización de los hijos (Baloyra y Martz, 1979: 46-49; Torres, 1980a: 268-ss).

El Cuadro I indica que la identificación partidista ha venido descendiendo desde su primera medición confiable en 1973. En el Cuadro II se observa que la familia partidizada es la que transfiere una imagen partidista a los hijos (Pereira, 1998b). Al aplicar el indicador demostrativo de la importancia familiar en la generación de imágenes político-partidistas a los hijos (diferencia entre el porcentaje de
CUADRO I

\begin{tabular}{|c|c|c|c|c|}
\hline \multicolumn{5}{|c|}{ LA IDENTIFIC ACION PARTIDISTA DE LOS VENEZZOL, ANOS $(1973-1994)$} \\
\hline $\begin{array}{l}\text { Nirel de tdentificarion } \\
\text { Partidista? }\end{array}$ & IDENTII & $\begin{array}{l}\text { ClON PA RTIDI } \\
\text { Nos AbsoluH }\end{array}$ & 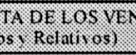 & OOI A NOS \\
\hline & $\begin{array}{l}\text { BALOYRA } \\
1073\end{array}$ & BATOBA 1983 & IEPDP $1993^{*}$ & IIDH $1994^{*}$ \\
\hline $\begin{array}{l}\text { Militante/ } \\
\text { Simpatizantc }\end{array}$ & $\begin{array}{c}739 \\
48.7 \% \\
\end{array}$ & $\begin{array}{c}683 \\
38.4 \%\end{array}$ & $\begin{array}{c}445 \\
29.8 \% \\
\end{array}$ & $\begin{array}{r}333 \\
22.7 \% \\
\end{array}$ \\
\hline $\begin{array}{l}\text { Independiente } / \\
\text { No intercsado }\end{array}$ & $\begin{array}{r}778 \\
51.3 \% \\
\end{array}$ & $\begin{array}{l}1.095 \\
61.6 \%\end{array}$ & $\begin{array}{r}1.048 \\
70.2 \% \\
\end{array}$ & $\begin{array}{r}1.133 \\
77.2 \% \\
\end{array}$ \\
\hline Casos Válidos & 1.517 & 1.778 & 1.493 & 1.466 \\
\hline Casos No Válidos & 4 & 11 & 6 & 34 \\
\hline Muestra Total & 1.521 & 1.789 & 1.499 & 1.500 \\
\hline
\end{tabular}

CUADRO II

\begin{tabular}{|c|c|c|c|c|c|c|}
\hline \multicolumn{7}{|c|}{ 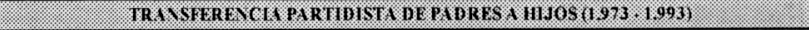 } \\
\hline \multirow{3}{*}{ 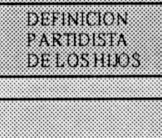 } & \multicolumn{6}{|c|}{ 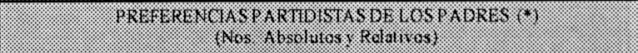 } \\
\hline & \multicolumn{2}{|c|}{ 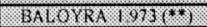 } & \multicolumn{2}{|c|}{ BATOBA 1983} & \multicolumn{2}{|c|}{ IEPDP P 1993} \\
\hline & Partidistas & $\begin{array}{c}\text { No: } \\
\text { Pantidisius }\end{array}$ & Partidistas & Partudistas & Pariofistas & Pantidisios \\
\hline PARTIDISTAS & $\begin{array}{c}278 \\
57.4 \%\end{array}$ & $\begin{array}{c}378 \\
45.4 \%\end{array}$ & $\begin{array}{c}428 \\
45.2 \% \\
\end{array}$ & $\begin{array}{c}129 \\
26,8 \% \\
\end{array}$ & $\begin{array}{c}392 \\
35.2 \% \\
\end{array}$ & $\begin{array}{c}19 \\
13.7 \% \\
\end{array}$ \\
\hline INDEPENDIENTES & $\begin{array}{c}206 \\
42.6 \% \\
\end{array}$ & $\begin{array}{c}454 \\
54.6 \% \\
\end{array}$ & $\begin{array}{c}518 \\
54.8 \% \\
\end{array}$ & $\begin{array}{c}352 \\
73,2 \% \\
\end{array}$ & $\begin{array}{r}722 \\
64.8 \% \\
\end{array}$ & $\begin{array}{c}120 \\
86.3 \% \\
\end{array}$ \\
\hline Casos Válidos & \multicolumn{2}{|c|}{1.316} & \multicolumn{2}{|c|}{$\begin{array}{c}1.427 \\
362\end{array}$} & \multicolumn{2}{|c|}{1.253} \\
\hline Casos No Välidos & \multirow{2}{*}{\multicolumn{2}{|c|}{205}} & \multirow{2}{*}{\multicolumn{2}{|c|}{$\frac{362}{36}$}} & \multirow{2}{*}{\multicolumn{2}{|c|}{246}} \\
\hline Significación $\left(\mathrm{X}^{-}\right)$ & & & & & & \\
\hline $\begin{array}{l}\text { Asociacion } \\
\text { Somers' } D_{\mathrm{yx}}\end{array}$ & \multicolumn{2}{|c|}{0.12005} & \multicolumn{2}{|c|}{0.18424} & \multicolumn{2}{|c|}{0.21519} \\
\hline
\end{tabular}

partidistas en familias politizadas y no politizadas) utilizado por Torres (1980a: 275), se obtiene que el mismo viene en aumento, ya que para la Encuesta Baloyra 73 esa diferencia es $12 \%$, para Batoba 83 es $18,4 \%$ y para IEPDP 93 es $21,5 \%$. La operación aritmética muestra que las diferencias aumentan a medida que el minuendo (porcentaje de partidistas en familias politizadas) se va haciendo mayor, lo cual verifica la importancia de la familia partidizada en la transferencia de una imagen partidista a los hijos.

También se deriva del Cuadro II que la transferencia partidista de los padres partidizados a los hijos viene en descenso desde 1973 a 1993 (57,4 \% en 1973, 45,2 \% en 1983 y $35,2 \%$ en 1993). Este descenso evidencia el debilitamiento de la fuerza de transmisión de lealtades partidistas a los hijos de la familia partidizada en el tiempo y el aumento de la transferencia de independencia política.

1. Esta encuesta fue administrada a nivel nacional a una muestra de 1200 personas. La misma forma parte de un estudio mundial de valores que realiza periódicamente un equipo internacional coordinado por el Prof. Ronald Inglehart de la Universidad de Michigan (USA). Para el caso venezolano, colaboraron en tal estudio el Instituto de Investigaciones y Estudios Políticos (IEPDP) de la Facultad de Ciencias Jurídicas y Políticas de La Universidad del Zulia (LUZ), La Universidad Simón Bolívar y la Fundación Polar.

2. La Encuesta Baloyra73 fue la primera medición confiable de actitudes políticas en el período democrático. Diseñada por los Profesores Enrique Baloyra y John Martz y administrada en noviembre de 1973 a una muestra nacional de 1500 personas. Los resultados fueron analizados por sus autores en el libro Political Attitudes in Venezuela. Societal Cleavages and Political Opinion, publicado en 1979, al cual se le considera un texto pionero en la temática. La Encuesta Batoba83, fue diseñada por los Profesores Enrique Baloyra y Arístides Torres y administrada en noviembre de 1983 a una muestra nacional de 2000 personas. Ambas encuestas pueden ser localizadas en el Banco de Datos de la Universidad Simón Bolívar en Caracas. La Encuesta IEPDP93 fue diseñada por el equipo de investigación en comportamiento político y electoral del Instituto de Estudios Políticos y Derecho Público (IEPDP) de la Universidad del Zulia (Maracaibo, Venezuela) y fue administrada en junio de 1993 a una muestra nacional de 1500 personas. La Encuesta de Valores 1995 fue identificada anteriormente. 
La fuerza de transmisión de independencia política de la familia no partidizada ha venido aumentando, superando ampliamente la medición de 1973 (54,6\% en Baloyra73, $73,2 \%$ en Batoba 83 y $86,3 \%$ en IEPDP93), cuando su fuerza de transmisión no era vigorosa, debido a que, superados los riesgos de los años 60 , la democracia incentivaba expectativas positivas y se transitaba la época de la consolidación del bipartidismo. Desde 1983, según refleja el Cuadro No. 2 , las variaciones de las medidas de asociación Somers' $\mathrm{D}_{\mathrm{yx}}$ son ascendentes porque aunque la independencia de los hijos de partidistas aumentó, el aumento mayor correspondió a la independencia de los hijos de independientes. La fuerza de ese incremento es más acentuada en 1993 por ello la asociación Somers' $\mathrm{D}_{\mathrm{yx}}$ correspondiente al cruce de las variables consideradas es más alta para la Encuesta IEPDP93 que para las anteriores.

El decrecimiento progresivo de la transferencia partidista de padres a hijos muestra que la familia venía reduciendo su influencia sobre la partidización de los hijos desde antes de la crisis de 1989, y ello tiene sus orígenes en la declinación de las lealtades partidistas por los efectos de la propia expansión económica y social y por los desatinados desempeños políticos.

Como efectos sociales de la reciente modernización ${ }^{3}$ y de la tradición distributiva y asistencial del Estado en Venezuela, se encuentran la expansión de la urbanización, la movilidad social y la generación de valores modernos (libertad, orientación al éxito, actitudes individualistas, etc.), que diversificaron las expectativas sociales e individuales constreñidas en la Venezuela autoritaria. Tales procesos llevaron a los partidos a minimizar las diferenciaciones sociales que en sus inicios representaban y se convirtieron en partidos nacionales policlasistas ${ }^{4}$, perdiendo con ello sus perfiles ideológicos.

La profesionalización de la actividad partidista contribuyó a la monopolización de la política y al clientelismo, ocasionando limitaciones a la extensión de la ciudadanía y prácticas partidistas internas no democráticas (Ramos Jiménez, 1997:203-208). Además, la escasa actualización les impidió estar en consonancia con las crecientes expectativas sociales. De allí que los partidos políticos tradicionales hayan renovado poco sus propuestas y conserven sus antiguas formas de hacer política que ya no conquistan adherentes y que debilitan la reproducción de lealtades partidistas en el proceso de socialización, provocando que los padres partidizados tengan una menor fuerza para transferir lealtades partidistas a los hijos.

El debilitamiento de la transferencia partidista no significa alejamiento de la política, por el contrario, se produce dentro de una convivencia social politizada, a juzgar por los datos obtenidos en la Encuesta IEPDP93 sobre la comunicación política de los entrevistados, donde la mayoría (superior al $60 \%$ en todos los casos) dijo tener alguna comunicación (mucho y poco) con su entorno (el padre, la madre, amigo (a), compañeros de trabajo y vecinos) sobre política. En particular las conversaciones sobre política se producen más $(73,2 \%)$ con el (la) amigo (a) más cercano (a) ${ }^{5}$.

Esa convivencia politizada que involucra a los diferentes agentes de socialización política ha coadyuvado para que la evaluación negativa de lo político se haya venido soli- dificando en el largo plazo, generándose un descontento endémico ${ }^{6}$. Para 1973 (Encuesta Baloyra73) era alta la confianza en las gestiones de gobierno, el 46,6\% consideró beneficiosos los últimos quince años de gobierno (Betancourt, Leoni y Caldera) y el 62,4\% eran optimistas sobre el nuevo gobierno (el primero de Carlos Andrés Pérez). En 1983 (Encuesta Batoba83), sólo el 10,6\% calificó como buenas las gestiones de gobierno hasta la fecha $(49,9 \%$ dijo regulares y 39,5\% malas). En 1993 (IEPDP93) el 88,7\% responsabilizó a los políticos de la crisis y el $51,5 \%$ evaluó como mala la democracia venezolana ${ }^{7}$.

Por otra parte, la partidización ha evolucionado hacia una relación más cercana con la definición ideológica de las personas. De la Encuesta Baloyra73 no se desprende significación al 0,05 ni asociación entre esas variables y en Batoba83 se detecta significación al 0,01, los derechistas son un poco más partidistas que los de centro e izquierda, pero la asociación Somersc $\mathrm{D}_{\mathrm{yx}}$ es irrelevante. Para 1993 el cruce es significativo al 0,0001 con baja asociación Somers屯 $D_{\mathrm{yx}}$ $(0,14686)$, los de centro e izquierda son mayoritariamente independientes y los de derecha un poco más partidistas. Es probable que la crisis del país esté colaborando en esas diferenciaciones.

3. La modernización entre los años 40 y 80 generó un gran impacto transformador en el país, Se produjo crecimiento social (demográfico y económico) que aumentó la capacidad social y política de la población (aumentó la mano de obra, se expandieron la alfabetización, los medios de comunicación y la participación electoral, entre otros) y también se elevaron las obligaciones públicas debido al incremento de las demandas sociales (Salamanca, 1997: 161-199).

4. En las democracias desarrolladas el descenso de los vínculos partidistas de los electores está asociado a los efectos sociales del desarrollo económico resultantes de la elevada producción de riqueza y la industrialización (Lipset, 1992: 119-129), que promovieron la urbanización, la educación, la expansión del mercado laboral y, en general, una gran apertura de la sociedad; y a la eficacia del Estado de Bienestar en mitigar las necesidades de la población, todo lo cual contribuyó a reducir las tensiones de las diferencias de clase. Los partidos políticos adoptaron posiciones ideológicas que difuminaron las diferencias de clase y religiosas que originalmente representaron (Dalton, 1996: 329-330; Hayes, 1995: 70). Esos cambios permitieron avanzar en el cumplimiento de metas sociales de largo plazo (Dalton, 1996: 330), pero también fragmentaron las antiguas bases sociales que apoyaban a los partidos políticos y aunque las diferencias de clase aún persisten, un cálculo más racional ligado a los valores postmaterialistas (surgimiento de nuevos temas de interés: ambientalistas, derechos femeninos, de los homosexuales, etc.) ha venido influenciando las preferencias de los votantes (Inglehart, 1984; Dalton, 1996: 319-337).

5. Cabe destacar que otro agente de socialización política importante son los medios de comunicación, de los cuales el más utilizado para informarse sobre la política, según refieren los entrevistados de la encuesta IEPDP93, es la TV., con una frecuencia de $52.7 \%$. Los medios de comunicación han sido políticamente muy críticos desde 1989, lo cual ha contribuido evidentemente a estimular el criticismo político en el país.

6. Molina (1997: 102) denomina descontento endémico al que se hace estable o permanente en el tiempo debido a la ineficacia gubernamental en situaciones de problemas económicos estructurales y deficiente industrialización, lo cual es propio de los países subdesarrollados.

7. A la pregunta de la Encuesta IEPDP93 que indagó sobre la principal cosa mala que la democracia le había dado al país, los entrevistados se manifestaron en un $35.8 \%$ por la corrupción y $22.7 \%$ por la pobreza, puede decirse sin embargo, que ambas respuestas se refieren a un mismo problema, el empobrecimiento de la población, ya que la molestia de los venezolanos por la corrupción no se debe tanto a su significado moral sino a que el despilfarro de recursos y la sustracción dolosa de los mismos han mermado la distribución de beneficios a la población. Según refiere Zapata (1996: 160-161) muchos piensan que los problemas económicos se deben a la corrupción y que al acabarse ésta los problemas económicos terminarían. 


\section{LA PREFERENCIA DEMOCRÁTICA}

La preferencia por la democracia en Venezuela tampoco está relacionada con las diferencias sociodemográficas de la población. La mayoría de los cruces respectivos obtenidos con base en la Encuesta IEPDP93 no arrojan significación ni asociación relevante. Sólo el cruce con edad es significativo al 0.01 , los más jóvenes son un poco más demócratas que los viejos ${ }^{8}$, pero la asociación Somers $₫ \mathrm{D}_{\mathrm{yx}}$ es irrelevante (0.03796) y no permite sostener una asociación cierta.

En las Encuestas Baloyra73 y Batoba83, la preferencia democrática tampoco aparece vinculada a las diferencias sociodemográficas. Pero en la Encuesta Baloyra73 se observan algunas diferencias muy pequeñas en los cruces de preferencia democrática con nivel de instrucción y sexo. El primero resulta significativo al 0.001 , los de menor nivel de instrucción son un poco menos demócratas que el resto, pero la asociación Somersc $D_{y x}$ es muy baja $(0.08261)$ y no se puede afirmar asociación concluyente. El segundo arroja significación al 0.05, los hombres son un poco más demócratas que las mujeres, pero el nivel de asociación Somers $₫ \mathrm{D}_{\mathrm{yx}}$ es también muy bajo (0.07249).

Entre 1958 y los años 60 se produjo un afianzamiento de la actitud hacia la democracia en correspondencia con los esfuerzos institucionales de consolidación democrática y de reducción de la amenaza izquierdista realizados en ese lapso. De allí que los residuos políticos actitudinales transicionales del período autoritario al demócrata se fueron deslindando a medida que el proceso democrático avanzó y superó los riesgos, lo cual se verifica con los resultados de la Encuesta Batoba83 donde la preferencia democrática tampoco aparece influenciada por ninguna diferencia sociodemográfica (sexo, edad, nivel de instrucción e ingreso). Ninguno de los cruces con las variables sociodemográficas resultó significativo al $0.05 \mathrm{ni}$ con asociación apreciable, lo cual es coherente con los resultados que se comentaron con base en la Encuesta IEPDP93.

A pesar del descontento y del descenso del partidismo, no se quebranta la actitud democrática porque permanece alta históricamente (Cuadro III). Para observar la influencia de la identificación partidista sobre la preferencia democrática, se realizaron los cruces respectivos con los datos de las Encuestas que se vienen comparando y se obtuvo que entre los partidistas y los independientes los porcentajes de preferencia democrática son altos, pero entre los independientes son ligeramente menores, es decir, la condición partidista favorece un poco más la preferencia democrática9. Tales cruces son significativos al 0.001 pero sus irrelevantes niveles de asociación Somers $c D_{y x}$ no permiten concluir asociación definitiva en ninguno de los casos.

En relación a la influencia de la partidización familiar sobre la preferencia democrática resultó que para la Encuesta Baloyra73 los entrevistados de padres partidizados (no se preguntó sobre la madre) preferían más la democracia y menos una forma de gobierno diferente. El cruce respectivo revela significación al 0.001 y aunque la asociación es baja (Somers $c \mathrm{D}_{\mathrm{yx}}=0.10658$ ) ella puede aceptarse, e indica que
CUADRO III

\begin{tabular}{|c|c|c|c|c|c|}
\hline \multicolumn{6}{|c|}{ 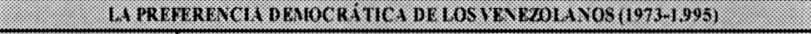 } \\
\hline \multirow[t]{2}{*}{ I REE ERENClA } & \multicolumn{5}{|c|}{ 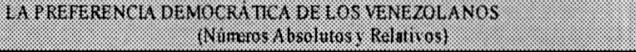 } \\
\hline & BALOYRA' & $\begin{array}{l}\text { BATOBA } \\
1983\end{array}$ & $\begin{array}{l}\text { IEDPDP } \\
1993\end{array}$ & $\begin{array}{l}\mathrm{IDH} \\
1994\end{array}$ & $\begin{array}{l}\text { VALORES } \\
1925\end{array}$ \\
\hline Democracia & $\begin{array}{c}929 \\
72.7 \% \\
\end{array}$ & $\begin{array}{l}1.471 \\
87.1 \% \\
\end{array}$ & $\begin{array}{l}1.133 \\
87.2 \% \\
\end{array}$ & $\begin{array}{r}1.134 \\
77.2 \% \\
\end{array}$ & $\begin{array}{l}1.003 \\
86.3 \% \\
\end{array}$ \\
\hline $\begin{array}{l}\text { Otros Sistemas } \\
\text { No Democráticos }\end{array}$ & $\begin{array}{r}349 \\
27.3 \% \\
\end{array}$ & $\begin{array}{c}218 \\
12.9 \% \\
\end{array}$ & $\begin{array}{c}167 \\
12.8 \% \\
\end{array}$ & $\begin{array}{r}335 \\
22.8 \% \\
\end{array}$ & $\begin{array}{c}159 \\
13.7 \% \\
\end{array}$ \\
\hline Casos No Válidos & $2+3$ & 100 & 199 & 31 & 38 \\
\hline Casos Válidos & 1.278 & 1.689 & 1.300 & 1.469 & 1.162 \\
\hline Muestra Total & 1.521 & 1.789 & 1.499 & 1.500 & 1.200 \\
\hline
\end{tabular}

la partidización de la generación anterior colaboraba a la adhesión democrática en 1973.

En ese tipo de cruce si hay variaciones posteriores, la preferencia por la democracia es casi la misma según sea la familia partidizada o no. De las Encuestas Batoba83 e IEPDP93 se deriva que no existen influencias de la partidización familiar sobre las preferencias democráticas de los entrevistados, el cruce sólo es significativo al 0.05 para Batoba83, pero los niveles de asociación Somers $c \mathrm{D}_{\mathrm{yx}}$ son irrelevantes.

Todos esos resultados refuerzan la solidez de la actitud democrática. Usualmente a eso se le denomina apoyo difuso, porque es más estable que el apoyo específico (a las gestiones de gobierno, por ejemplo) que puede variar (Torres, 1991: 174). Pero, el descontento endémico en el país podría afectar eventualmente el apoyo a la democracia, en especial si la actitud independiente se vuelve antidemocrática (descontento extremista, actitudes autoritarias). De hecho, los estudios de las actitudes políticas en los últimos años en Venezuela muestran que alrededor de una tercera parte de los entrevistados señalan que la democracia debe mejorarse (Torres,1991: 175; Pereira, 1996: 95-96).

En las Encuestas Batoba83 e IEPDP93 los cruces de preferencia democrática y ubicación ideológica presentan significación al 0,0001 y 0,01 respectivamente, así como asociación Somers $₫ \mathrm{D}_{\mathrm{yx}}$ baja $(0,26508$ y 0,14686$)$; ambos cruces señalan una preferencia por la democracia superior al $70 \%$ entre todos los grupos de ubicación ideológica, pero entre los izquierdistas existe un poco menos de apego democrático porque se manifiestan un poco más por un cambio de sistema.

8. Si se considera que los individuos de 40 años y más vivieron su proceso de socialización política primario entre los años 50 y 60 , es decir, entre el período autoritario y la fase de mayores riesgos para la democracia (recuérdese también el auge que tuvo el movimiento perezjimenista, la Unión Cívica Nacionalista en 1968), es explicable que ese segmento tienda a ser un poco menos demócrata y si, además, se agrega el descontento, todo ello puede ocasionar reminiscencias autoritarias.

9. Con base en la Encuesta IEPDP93, Welsch y Carrasquero (1996: 63-68) señalan que la legitimidad normativa (actitud democrática) está influida por la adhesión a un partido. La pregunta de la encuesta que en ese trabajo representa la legitimidad normativa es evaluación de la democracia. Por eso el resultado es diferente al que aquí se analiza, aunque no es contradictorio, ya que la orientación de los cruces es la misma, pero la asociación en Welsch y Carrasquero es un poco mayor, asociación positiva baja, según la Tabla interpretativa de Richard Cole adaptada de la originalmente presentada por James Davis (Cole, 1980:Tabla 7.12). 


\section{EL ESTILO PROCEDIMENTAL DE LA DEMO- CRACIA EN VENEZUELA}

La democracia venezolana ha estado basada exclusivamente en el modelo representativo ya que, quienes diseñaron la Constitución de 1961 optaron por el modelo representativo liberal, el cual asigna autonomía a los representantes frente al electorado, de esa forma, la participación popular se limita casi exclusivamente a la elección de los gobernantes y no a la escogencia de las orientaciones políticas ni al control de la gestión (Molina, 1985: 178-183; Fernández Toro, 1994: 110).

En correspondencia con el modelo de democracia representativa que el país ha desarrollado, se observa una identificación democrática de carácter procedimental o como método para resolver asuntos de gobierno (Pereira, 1998c), porque las respuestas mayoritarias de los entrevistados de la Encuesta IEPDP93 a la pregunta sobre la característica mas positiva de la democracia son la libertad ${ }^{10}(40,2 \%)$ y la elección de los gobernantes $(22 \%)$, características que son esenciales en la definición procesal o procedimental de la democracia (Bobbio y Matteucci, 1985: 503; Bobbio,1992: 14-16; Dahl, 1991: 266-267) que remiten más a los preceptos de la democracia liberal y menos a las orientaciones de la democracia social, debido a que las respuestas dirigidas a las alternativas igualdad ante la ley y solidaridad social de la pregunta antes dicha alcanzaron frecuencias minoritarias $(14,7 \% \text { y } 12,7 \% \text { respectivamente })^{11}$. Acogiendo la línea argumentativa de Sartori, esos rasgos liberales de la preferencia democrática de los entrevistados pueden entenderse como valores "sumamente preferibles" (Sartori, 1988: 338). Este hallazgo sorprende debido a que la democracia venezolana se ha desarrollado con discursos políticos de fuerte énfasis distributivo y los éxitos al respecto han sido bastante limitados.

La libertad como valor democrático se puede interpretar además como rechazo a la opresión, en tanto que, sobre la pregunta de la encuesta que se comenta referida a la característica negativa mas importante de la dictadura, el valor modal lo obtuvo, precisamente, la inexistencia de libertad $(42 \%)$, la característica opuesta a la que aluden positivamente para la democracia. $\mathrm{Al}$ agregarse los que señalaron la represión $(16,8 \%)$, que es una forma de no libertad, esa respuesta es aún mayor, $58,8 \%$.

Las respuestas más frecuentes a la pregunta de la Encuesta IEPDP93 que solicitaba la característica política más importante de la democracia, fueron la libertad de pensamiento y acción $(30,2 \%)$ y la responsabilidad de los gobernantes ante el pueblo $(25,2 \%)$, que expresan los rasgos medulares de la democracia procesal: libertad extensa, incluida la libertad de oposición y los estímulos de gratificación electoral que, en un sistema democrático, incitan a los gobernantes a cumplir sus promesas (Popper, 1995: 176; Dahl, 1991: 266).

A pesar de que hasta 1988 el comportamiento político y electoral de los venezolanos estuvo determinado básicamente por la identificación partidista (Baloyra y Martz, 1979; Torres, 1980), la valoración de la responsabilidad de los gobernantes también estuvo presente y le dió continuidad a la democracia, ya que, desde 1973 hasta 1983 hubo alternancia electoral entre los partidos AD y COPEI, dentro de un comportamiento conocido como "voto castigo", es decir, voto contra el otro, contra las gestiones de gobierno que no satisfacían las expectativas de los electores. En las condiciones actuales de desencanto de los ciudadanos con las gestiones de gobierno, la valoración de la responsabilidad de los gobernantes sigue gravitando pero con mayor fuerza y se manifiesta en la apatía, la abstención, el descontento, la declinación de las lealtades partidistas y la desalineación electoral, aunque permanece alta la preferencia democrática.

Los resultados de los cruces de las preguntas comentadas con las características sociodemográficas (sexo, edad, ingreso, nivel de instrucción y ocupación) y autoubicación ideológica (derecha, centro e izquierda) no indican efectos importantes ${ }^{12}$, la mayoría de los cruces no resultaron estadísticamente significativos al 0.05 y ninguno alcanzó niveles relevantes de asociación ${ }^{13}$.

Puede decirse, entonces, que aunque se entiende que las diferenciaciones en la población existen y ellas pueden darle determinados énfasis al comportamiento democrático entre determinado grupo de personas, con base en los datos que se manejan (Encuesta IEPDP93), esas diferenciaciones no arrojaron influencias estadísticamente significativas como para concluir influencia cierta. Ese comportamiento encaja con el señalado históricamente para la identificación partidista y democrática, expuesto líneas arriba, y reitera la fuerza del proceso de socialización política desarrollado en el período de consolidación de la democracia en Venezuela.

Sin embargo, dado el descenso de la identificación partidista y el aumento del descontento, los venezolanos están ahora mas expuestos al devenir de la realidad social y política debido al vacío mediador que han dejado los partidos políticos (Pereira, 1996). Esto deriva en la posibilidad de cambios para los próximos años, en los cuales podrían contrastarse

10. La libertad ha sido reportada en varios trabajos de investigación en Venezuela como un valor importante en la percepción de la democracia, que refuerza la opción democrática frente a otros sistemas políticos (Pereira, 1995; Zapata, 1995: 48-51; Welsch y Carrasquero, 1996: 58). En otra pregunta de la Encuesta IEPDP93 que solicitaba la principal cosa buena que la democracia le había dado al país, los entrevistados se manifestaron en un $66.4 \%$ por la libertad.

11. En los resultados de otro estudio denominado "Los valores de los venezolanos" (Zapata, 1995: 11), se reporta un hallazgo similar; Ante el dilema libertad (cada quien pueda vivir y desarrollarse sin obstáculos) e igualdad (nadie se vea desfavorecido, que las diferencias no sean tan grandes), los entrevistados prefirieron mas a la libertad (54\%) que a la igualdad $(33 \%)$.

11. La indiferenciación ideológica de la valoración de la democracia, imprime un sentido ideológico neutro a la preferencia democrática de los venezolanos que ratifica su sentido procedimental

12. Gladys Villarroel (1996), utilizando la metodología de análisis factorial, encuentra que la libertad y otras valoraciones sustantivas de la democracia son importantes en un grupo de entrevistados y revela asociaciones de esos aspectos con variables sociodemográficas. Sin embargo, sus conclusiones se basan en una submuestra $(n=342)$ del Dto. Federal y Edo. Miranda (p. 232), por lo cual no es posible extender conclusiones nacionales y no utiliza medidas de asociación que validen la influencia, lo cual sería necesario conocer para aceptar la supuesta influencia.

13. Esta dirección cambia la lógica inicial que se le dio a la variable, es decir, en el marco de posiciones ideológicamente opuestas quienes piensan que la pobreza se debe a la flojera deberían ser menos igualitaristas y quienes opinan que se debe a la injusticia social deberían ser más igualitaristas y el resultado ha sido el opuesto. 
mejor las tendencias de las actitudes políticas venezolanas y sus repercusiones sobre la actitud hacia la democracia.

\section{LA INCLINACIÓN ESTATISTA}

Con base en la Encuesta IEPDP93 se obtiene que los entrevistados manifiestan una marcada inclinación a aceptar una fuerte presencia del Estado en la sociedad, ya que a la pregunta que indagaba si el Estado debería tener una mayor, igual o menor presencia en los asuntos del país, sus respuestas se agruparon en un $79 \%$ en torno a las alternativas mayor e igual. Puede decirse entonces, que en Venezuela existe una tendencia ideológica que identifica a los individuos con un modo estatista de organización de la sociedad, modos que a la final identifican a las sociedades debido a sus procesos sociohistóricos particulares; la tendencia estatista por ejemplo, predomina entre los alemanes, pero en Estados Unidos prevalece el individualismo (Wegener, 1996: 185).

En Venezuela el Estado fuerte ha sido la regla en el presente siglo y ha acompañado a la democracia desde su nacimiento formal en 1958, llevando un gran peso en la distribución de la riqueza, la negociación, la resolución de conflictos, el proteccionismo y el clientelismo, basado en la gran renta petrolera y el elevado gasto y empleo público (Rey, 1988, 1991; Borges, 1992; Kornblit, 1996).

Los valores de significación y asociación (Somers' $\mathrm{D}_{\mathrm{yx}}$ ) obtenidos de los cruces de la variable presencia del Estado con las variables sociodemográficas (sexo, edad, ingreso, nivel de instrucción y ocupación) y autoubicación ideológica (derecha, centro e izquierda), no constituyen evidencias contundentes de influencia entre esas variables. Aunque la mitad de los cruces resultaron significativos al 0,05, las medidas de asociación resultantes no indican influencia relevante. Las características que ofrecen los cruces que resultaron significativos son: los grupos de mayores ingresos, los más instruidos y del sector ocupacional no manual acogen un poco más la alternativa menor presencia del Estado, en contraste, los de menores ingresos, niveles bajos de instrucción y sectores ocupacionales manuales la favorecen menos. Pero debido a que tales cruces no arrojaron niveles relevantes de asociación, se concluye que las diferencias sociodemográficas e ideológicas no producen diferencias estadísticamente significativas sobre las valoraciones mayor, igual o menor presencia del Estado de los entrevistados.

La preferencia estatista indica una fuerte delegación en el Estado de las decisiones públicas en el país y puede entenderse como antitético a la profundización de la democracia en tanto que constituye un obstáculo para que el poder fluya desde la base hacia el vértice, como lo presupone el sistema de poder democrático (Bobbio, 1992:27). Pero el mismo proceso de democratización ha construido sus propios obstáculos, ya que ha impulsado la expansión del Estado hacia una diversidad de funciones de protección de amplios sectores sociales, y eso ha reducido las posibilidades de participación de todos en la toma de decisiones, porque los procesos se han especializado, requiriéndose el desempeño de expertos y no de la gente común (Bobbio, 1992: 26-27).
A la final ese proceso también favorece el desarrollo de la democracia representativa, ya que no todos los individuos pueden tener las habilidades pertinentes para el entendimiento de todos los asuntos públicos. De hecho, esa situación reta la profundización de la democracia en la actualidad, ya que se entiende la democracia representativa como necesaria pero se reconoce su insuficiencia para garantizar la soberanía del pueblo en los diferentes niveles de la decisión política. Miró Quesada (1996: 135) apunta a la necesaria convivencia de la democracia representativa con la democracia directa como vía para democratizar la democracia. De hecho, la profundización de la democracia en el país se ha vinculado a la ampliación de la participación, para lo cual han sido recomendados diferentes mecanismos directos y semidirectos de participación (Fernández Toro, 1994: 132 135; Rivas Quintero, 1994:150-154; Rivero Lozada, 1994: 511-519; Linares Benzo, 1991: 95-96).

En otro trabajo (Pereira, 1996) y con base en la Encuesta IEPDP93, se mostró que la gran mayoría de los entrevistados culpabilizaban a los políticos y no a la democracia de la crisis del país. Sin embargo, una actitud mas participativa no se evidenciaba entre ellos. A pesar de que muchos dijeron que cada venezolano debía contribuir a que la democracia superara sus problemas $(72.5 \%)$ y en menor medida otros dijeron que eso era asunto de los políticos $(27.5 \%)$, al preguntárseles qué podrían hacer concretamente, $49.9 \%$ expresó trabajar, $13.2 \%$ votar y $9.6 \%$ dijo nada, entre otras respuestas minoritarias. Para una buena parte de los entrevistados participar en la resolución de los problemas de la democracia es un deber pero desde su mundo privado (realizando sus tareas habituales) y para muy pocos por la participación directa en el medio público.

Esa reducción de los ciudadanos a su medio privado implica la delegación del espacio público al Estado y a los políticos e indica los límites del entendimiento de la libertad, ya que no la extienden hacia los órganos del poder, lo que refleja la orientación individualista de la libertad de gran parte de los entrevistados, de libre albedrío, que se realiza plenamente en el espacio privado, no significa proximidad al medio público. Esa situación coloca a la democracia venezolana en el marco de los problemas de la democracia liberal, porque la complejidad de problemas y funciones que implica la acción pública colabora al entendimiento de la libertad como goce privado (Dunn, 1992: 46-53), generándose la tensión inevitable entre los presupuestos que rigen la libertad en las democracias modernas, esto es, entre la libertad de los ciudadanos de participar en la política como mecanismo de autodefensa contra el gobierno y la libertad de retirarse a su mundo privado y no participar si así lo desean (Goodwin, 1987: 58-59).

\section{LA JUSTICIA SOCIAL}

Las investigaciones sobre la conducta política de los venezolanos realizadas entre los años 70 y 80 no encontraron influencias significativas de las desigualdades sociales con base en la posición de clase en las preferencias partidista y democrática (Baloyra y Martz, 1979: 46-49; Torres, 1978: 12-17; Torres, 1980: 31-43; Torres, 1982). 
La hegemonía capitalista se afianzó en el período democrático con un proyecto político de reducción del conflicto social y de modernizacion y movilidad social, lo cual se hizo posible debido a la consolidación de una ideología de centro derecha (Molina, 1992: 74-77). Las diferencias ideológicas de los venezolanos en el continunn derecha-izquierda se manifestaron claramente en los años 80 , cuando los derechistas aparecían reafirmando sus preferencias por el capitalismo y los izquierdistas por el socialismo; en contraposición al comportamiento observado en los años 70 cuando la preferencia por el socialismo era mayor (Codetta, 1990: 100). Asimismo, en los 80 la concentración de derechistas en torno a $\mathrm{AD}$ y COPEI era ampliamente mayoritaria y la concentración de izquierdistas en torno a los partidos de izquierda era consistente pero minoritaria; además, entre los simpatizantes de partidos de izquierda venía ocurriendo un desplazamiento hacia ubicaciones ideológicas centristas (Codetta, 1990: 106-109).

Para 1993, de acuerdo a cálculos propios hechos con base en la Encuesta IEPDP93 esa tendencia indicada se mantiene con variaciones respecto a partidos de izquierda, los simpatizantes del Movimiento Al Socialismo (MAS) que se ubican como ideológicamente de derecha aumentan y disminuyen los que se ubican al centro. En la Causa Radical (Causa R) predomina la ubicación de izquierda de sus simpatizantes pero con una alta proporción de centristas, incluso mayor a la que presentan individualmente AD y COPEI. Estos cambios muestran que el avance del proceso democrático diluyó los radicalismos ideológicos en las preferencias por los partidos y moldeó una ideología de derecha, de centro derecha y de centro izquierda ligada a la aceptación del ordenamiento capitalista aunque en los dos últimos casos de manera moderada. Esta situación puede variar en el futuro de acuerdo a los cambios que el sistema de partidos muestra en las elecciones de 1998, pero su examen todavía debe esperar un tiempo prudencial.

En la búsqueda de otras diferencias ideológicas que pudieran estar ocurriendo en la población por efectos de las marcadas desigualdades sociales que se han originado por la crisis económica del país, se realizó un modelo de regresión logística con base en la Encuesta Nacional de Valores 1995, a objeto de establecer si existe entre los venezolanos, de acuerdo a sus posiciones de clase, a sus apreciaciones sobre la riqueza, sobre quién debe tener la mayor responsabilidad en asegurar el sustento de vida y sobre las distinciones de las causas de la pobreza, dos posturas ideológicas en torno a la igualdad, entendida ésta como acuerdo o desacuerdo con que deberían haber menos diferencias de ingresos entre los individuos (Pereira, 1998a).

La variable dependiente del modelo de Regresión Logit es "la igualdad" representada por el indicador dicotómico Acuerdo-desacuerdo con que debería haber menos diferencias de ingresos entre los individuos (Acuerdo $=1$, desacuerdo $=0$ ). Las variables independientes son: "responsabilidad del sustento de vida (gobierno-individuos)”, medida por el indicador dicotómico ¿Es responsabilidad del gobierno o de los individuos asegurar el sustento de vida? (Responsabilidad del gobierno $=1$, responsabilidad de los individuos $=0$ ), "percepción de la riqueza (explotación o logro individual)", medida por el indicador dicotómico ¿la riqueza se hace a costa de los demás o puede crecer para todos? (se hace a costa de los demás=1, puede crecer para todos $=0$ ), "causas de la pobreza (injusticia social o flojera)", representada por el indicador dicotómico los individuos son pobres por que son flojos o porque la sociedad es injusta (la sociedad es injusta $=1$, flojera $=0$ ) y "clase social objetiva" representada por el índice ordinal de clase (clase baja, media y alta).

La tendencia esperada sería que aquellas personas de clase social baja, que consideran que la riqueza se hace a costa de los demás (explotación), que identifican al gobierno como el mayor responsable en garantizar el sustento de vida y que señalan la injusticia social como causa de la pobreza, tendrían mayores probabilidades de aceptar menos diferencias en los ingresos de las personas y podrían calificarse de orientación igualitarista. Aquellos de clase social alta, que piensan que la riqueza puede crecer para todos, que señalan a los individuos como los responsables de su sustento de vida y a la flojera como causa de la pobreza, tendrían menores probabilidades de aceptar menos diferencias en los ingresos de las personas y por lo tanto, podrían calificarse como no igualitaristas.

El modelo de regresión logística (Cuadro IV) es significativo al 0.0001 y tiene una solidez aceptable porque logra predecir diferencias en torno a la igualdad, aunque no totalmente en relación a las diferencias esperadas. Por una parte, cuando las personas piensan que el gobierno debe tener la mayor responsabilidad en asegurar el sustento de vida, pertenecen a la clase social baja, opinan que la riqueza se hace a costa de los demás y que los pobres son tales porque son flojos ${ }^{14}$, la probabilidad de acuerdo con que existan menos diferencias de ingreso es mayor ( $\mathrm{P}=0,78732$ ), son más igualitaristas. Eso implica que con base en los datos que se manejan alrededor del $78 \%$ de quienes tienen esas características mencionadas son más igualitaristas.

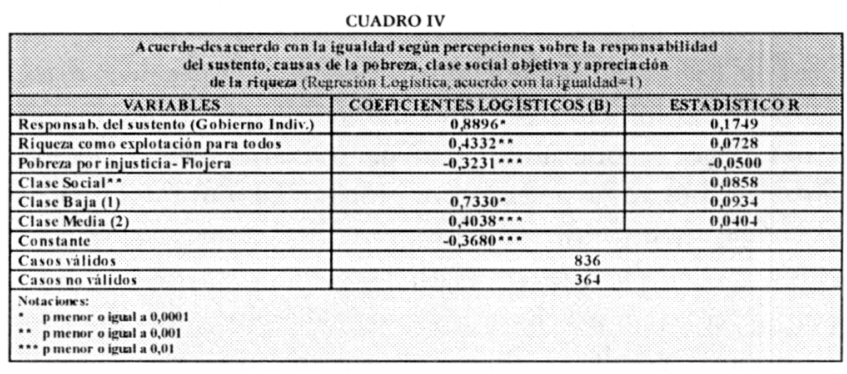

Por otra parte, cuando las personas piensan que la mayor responsabilidad en asegurar el sustento de vida la tienen los propios individuos, pertenecen a estratos sociales altos, opinan que la riqueza puede crecer para todos y que los pobres son tales debido a la injusticia social, la probabilidad

14. Inicialmente fueron también consideradas para integrar el modelo otras variables, pero no resultaron significativas y fueron descartadas. Esas variables fueron las sociodemográficas (sexo, edad, nivel de instrucción y ocupación), autoubicación ideológica y las referidas a valoraciones políticas y sociales: la actitud democrática, modernismo, religiosidad, funcionamiento del sistema económico en la democracia, el manejo del país por minorías poderosas, chance de salir de la pobreza, entre otras. 
de aceptar menores diferencias de ingresos es menor ( $\mathrm{P}=$ 0,25539 ), son menos igualitaristas. Es decir, con base en los datos que se manejan aproximadamente el $25 \%$ de quienes tienen las características descritas son menos igualitaristas.

Entre los hallazgos que presenta el modelo se encuentra que en la apreciación de la igualdad la variable de mayor fuerza es "responsabilidad del sustento de vida (gobiernoindividuos)" ( $\mathrm{R}=0,1749)$ y no la variable clase social objetiva. Ese resultado expresa el impacto diferenciado que ha producido en la población el papel distributivo del Estado desempeñado por las distintas administraciones de gobierno, que a partir de los años 80 y al calor de la crisis han provocado polémicas públicas respecto de si la presencia del Estado en el país debe ser mayor o menor a los efectos de alcanzar un mejor orden social. Puede entenderse que tales procesos han dejado una huella que se manifiesta en la acentuada influencia de la dualidad estatismo-individualismo en las diferenciaciones de las personas respecto de la igualdad.

En las democracias desarrolladas las diferenciaciones de clase aparecen debilitadas pero continúan manifestándose de nuevas formas; las evidencias muestran que hoy en día la influencia de temas relacionados con las divisiones de clase se mantienen en el electorado y se les han agregado otras preocupaciones (Dalton, 1996: 319-337). Bernardette Hayes (1995: 75-87) analiza la influencia de la variable clase social sobre un conjunto de actitudes políticas en Gran Bretaña, Australia, Alemania Occidental y Estados Unidos y obtiene que esa influencia existe pero no es determinante ni de la misma intensidad en todos los casos.

En el modelo de regresión que se comenta también se obtiene que la clase social tiene su influencia pero ocupa el segundo lugar de importancia $(R=0,0858)$ y particularmente el valor categórico clase baja $(R=0,0934)$, lo cual indica que pertenecer a estratos sociales bajos agrega un poco más de estímulo a la aceptación de la igualdad. Las variables "percepción de la riqueza" $(\mathrm{R}=0,0728)$ y "causas de la pobreza" $(R=-0,05)$, tienen menor fuerza y por tanto menor influencia.

Los igualitaristas están orientados por una visión estatista del bienestar que encuadra con valoraciones de la riqueza como explotación. Resulta compatible que el Estado deba tener mayor responsabilidad en garantizar el sustento de vida entre las personas de baja posición social, también la necesidad de protección es coherente con la percepción de la riqueza en un sentido perjudicial para la mayoría (riqueza como explotación). Para los no igualitaristas, de alta posición social, resulta también congruente que la responsabilidad del sustento de vida recaiga sobre el individuo, ya que la riqueza es apreciada como un logro individual alcanzable (puede crecer para todos) que se puede obtener con el esfuerzo individual, sin el concurso del gobierno.

Otro resultado inesperado del modelo de regresión logística es el comportamiento inverso de la variable causa de la pobreza. Se esperaba que quienes atribuyeran la pobreza a la injusticia social (criterio estructural) fueran más igualitaristas y quienes la atribuyeran a la flojera (criterio individualista) fueran menos igualitaristas, pero el resultado es incoherente, quienes señalaron la flojera resultan más igualitaristas y quienes indicaron la injusticia social lo son menos $(\mathrm{R}=-0,05)$.
Converse (1964: 244-245) concluyó respecto al público norteamericano que las personas pueden tener actitudes incoherentes por falta de información o desinterés, e incluso cuando los temas relacionados con la actitud que se pretende medir han estado sometidos a controversia política por largo tiempo. En este caso puede decirse que entre las razones que pueden generar incoherencias ideológicas está la alienación, concepto de base marxista que designa el proceso de extrañamiento entre el individuo y su medio social objetivo, que lo lleva a asumir conductas y actitudes fatalistas y acríticas como lo señala Maritza Montero (1987: 57 70) en su análisis de la conducta social en Venezuela.

Pero tanto las diferencias como las incoherencias observadas en el modelo descrito deben ser profundizadas en investigaciones sucesivas, más aún cuando los resultados permiten pensar en la posibilidad de que las diferenciaciones ideológicas y sociales respecto del tema distributivo influyan en el delineamiento de orientaciones ideológicas de mayor trascendencia política en el país, que podrían repercutir en el sistema político.

\section{CONCLUSIONES}

Las actitudes políticas de los venezolanos presentan cambios significativos en los años noventa como producto del desarrollo democrático, entre los cuales están:

1- La familia continúa estando vinculada a la reproducción de lealtades partidistas en Venezuela, como lo verificaron en su momento Baloyra-Martz y Arístides Torres. Pero, la familia partidizada ha perdido fuerza en la transferencia de lealtades partidistas a los hijos en el lapso que transcurre entre 1973 y 1993; asimismo, la familia no partidizada ha incrementado su fuerza de transmisión de independencia política.Tal proceso ha ocurrido en un ambiente politizado, donde todos los agentes de socialización política han contribuido a la evaluación negativa de lo político y se ha quebrado el apoyo específico a las gestiones de gobierno, a los partidos y a los políticos. Esto ha impactado el proceso de socialización dando lugar a una transformación cultural de la socialización política de los venezolanos, signada por el descenso del partidismo y el incremento de posiciones independientes. Habiendo estado la familia vinculada de manera importante a la reproducción de lealtades partidistas duraderas en el país, puede decirse que el debilitamiento de esa función significa un duro revés para la persistencia de lealtades partidistas en el tiempo. Desde las elecciones nacionales de 1993 han aparecido nuevos partidos, pero todavía no han logrado establecer lealtades duraderas con la población. Habrá que observar sus trayectorias en el tiempo para derivar tendencias.

2- Hasta ahora, la actitud democrática no se ha visto seriamente afectada, ella es independiente de influencias sociodemográficas y de la partidización y se basa en la aceptación de los valores de la modernidad, es decir, los valores que respaldan a la democracia como forma de gobierno (libertad y elección de los gobernantes), pero la orientación es de tipo procedimental. Dado el convencimiento democrático existente en un contexto de alto descontento, de 
declinación de las identificaciones partidistas y de desaciertos de los partidos, se ha favorecido la personalización de la política lo cual puede generar sentimientos de inutilidad en torno a la figura del político y la magnificación de las cualidades de los expertos (Perelli, 1995: 176) o de los poseedores del carisma, conduciendo esto a la despolitización de la política, al manejo tecnocrático exclusionista de lo público y a perturbaciones en la institucionalidad por efectos de los sesgos autoritarios. Los sesgos autoritarios mermarían cualitativamente la democracia en Venezuela y, si logra mantener un clima de libertades individuales, podría contar con la anuencia pasiva de la población, dado el entendimiento procedimental existente de la democracia.

3- Se están produciendo divisiones ideológicas y sociales en la actitud de los venezolanos hacia la igualdad que de acuerdo al modelo logístico resultante, está promovido con mayor fuerza por una variable de tipo ideológico como es la preferencia estatista-individualista del bienestar y menos por la clase social objetiva, que ocupa el segundo lugar de influencia. Se percibe que los venezolanos gravitan sobre temas trascendentes estrechamente vinculados a las opciones dilemáticas que el país enfrenta (más o menos intervención estatal), más allá de sus particulares condiciones de clase (aunque la incluye), lo cual indica un buen nivel de información en la población, no obstante que no son temas post-materialistas.

$\mathrm{El}$ acento liberal que acompaña la valorización de la democracia entre los venezolanos sugiere que el descontento contra los gobiernos y lo político pudiera estar movilizado por la búsqueda del bienestar y no por la puja hacia la igualdad, en tanto que objetivo doctrinario. El bienestar que es exigido al medio público está referido a las garantías de seguridad (material, individual) que los individuos requieren para proteger su goce privado y es esto lo que está amenazado por la crisis y por tanto promueve exigencias de mejoramiento en la distribución del ingreso. De allí que podría no ser permanente la fuerza del reclamo por decisiones públicas más distributivas de un sector de la población, también podría debilitarse si se produjeran mejores condiciones de vida, como demuestran los estudios que ocurrió en Europa Occidental y Estados Unidos por efectos del Estado de Bienestar (Lipset y Rokkan, 1992: 253-254).

Pero la profundización de las diferenciaciones sociales por efectos de la desigual distribución de los ingresos podría promover variaciones tanto en el espectro ideológico (centro derecha y centro izquierda) que ha servido de atenuante a los extremismos políticos en el país, como en otras representaciones ideológicas, trayendo cambios significativos en el ordenamiento democrático vigente.

\section{BIBLIOGRAFÍA}

Baloyra, E. y Martz, J. (1979): Political Attitudes in Venezuela. Societal Cleavages and Political Opinion. Austin: University of Texas Press.

BobBIO, N. (1992): El futuro de la democracia. Bogotá: Fondo de Cultura Económica.

Bobbio, N. y Matteucci, N. (1985): Diccionario de Política. 4ta. edic. en español. España: Siglo XXI Editores.
BORGES, W. (1992): "El modelo político venezolano: los fundamentos del consenso y la realidad actual". Cuestiones Políticas, 9: 83-105.

Codetta, C. (1990): La Ideología Política del Venezolano. Caracas: Coediciones Universidad Simón Bolívar y Congreso de la República.

COLE, R. (1980): Introduction to Political Enquiry. New York: Macmillan.

Converse, P. E. (1964): "The Nature of Belief Systems in Mass Publics”. En: APTER, David (Edit.): Ideology and Discontent . London: The Free Press of Glencoe. Pp. 206-261.

Crisp, B.; Levine, D. y Rey, J. C. (1996): "El problema de la legitimidad en Venezuela”. Cuestiones Políticas, 16: 5-43.

DAHL, R. (1991): La democracia y sus críticos. Buenos Aires: Editorial Paidós.

Dalton, R. J. (1996): "Political cleavages, issues, and electoral change”. En: Le Duc, L.; NIEMI, R. G., y NorRIS, P. (Comps.): Comparing Democracies. Elections and voting in global perspective. California: SAGE Publications. Pp. 319-342.

Dunn, J. (1992): "La libertad como valor político sustantivo”. En: Castro Leiva, L. (Comp.): El liberalismo como problema. Caracas: Monte Avila Editores.

F.A.C.E.S. (1982): Boletín de Indicadores Socioeconómicos. Vol.1, No. 2. Caracas: U.C.V.

FERNÁNDEZ TORO, J. C. (1994): "De la democracia insuficiente a la democracia plena". En: COPRE: Una Constitución para el ciudadano. Caracas: Editorial Texto. Pp. 107-135.

GoODWING, B. (1987): El uso de las ideas políticas. Madrid: Ediciones Península.

HAYES, B. C. (1995): "The impact of class on political attitudes". European Journal of Political Research, 27, 69-91.

INGLEHART, R. (1984): "Changing cleavage alignments in western democracies”. En: Dalton, R.; Flanagan, S. y BECK, P. (Comps.): Electoral Change in Advanced Industrial Democracies. Princeton: Princeton University Press.

Kornblit, M. (1996): "Crisis y transformación del sistema político: Nuevas reglas y viejas reglas del juego”. En: Alvarez A. (Comp.): El sistema politico venezolano: Crisis y transformaciones. Caracas: U.C.V. Pp.1-31.

LinAREs Benzo, G. (1991): "La Constitución de 1961 y la Reforma del Estado”. En: Copre: Constitución y Reforma. Un proyecto de Estado Social y Democrático de Derecho. Caracas. Pp. 193-252.

LIPSET, S. M. (1992): "Algunos requisitos sociales de la democracia: Desarrollo económico y legitimidad política”. En: Almond, G; Dahl, R.; Downs, A. y Otros: Diez Textos Básicos de Ciencia Política. Barcelona: Edit. Ariel, S.A.. Pp. 113-150.

Maxim Ross y Asociados, S.A. (1989): Informe de Coyuntura y Politica Económica. Boletín Mensual, 1. Caracas.

Miró QuesadA, F. (1996): "Democracia Directa: un análisis comparado en las Constituciones Latinoamericanas". En: COmbellas, R. (Comp.): El Nuevo Derecho Constitucional Latinoamericano. Caracas: Edit. Panapo. Pp. 131-156. 
MolinA, J. E. (1997): "El efecto electoral del subdesarrollo. Cambios de gobierno y sus causas en América Latina, el Caribe y los países industrializados". Cuademos del CENDES, 36, 87-108.

- (1992): "El proceso de la consolidación de la hegemonía en Venezuela y sus consecuencias políticas". Cuestiones Políticas, 9, 73-81.

- (1985): "Democracia representativa y participación política en Venezuela". Cuestiones Políticas, 1, 177-209.

MolinA, J. y PÉrEZ, C. (1996): "Los procesos electorales y la evolución del sistema de partidos en Venezuela”. En: Alvarez, A. (Comp): El sistema político venezolano: Crisis y transformaciones. Caracas: U.C.V. Pp. 193-238.

- (1994): "Venezuela: ¿Un nuevo sistema de partidos?. Las elecciones de 1993". Cuestiones Políticas, 13, 63-89.

Montero, Maritza (1987). Ideología, Alienación e Identidad Nacional. Una Aproximación psicosocial al Ser Venezolano. Caracas: U.C.V., Ediciones de la Biblioteca.

PEREIRA, V. (1998a): Justicia y equidad en las actitudes de los venezolanos. Ponencia presentada en el XXI Congreso de la Asociación de Estudios Latinoamericanos (LASA), Chicago, Illinois, del 24 al 26 de septiembre.

- (1998b): Problemas familiares de los partidos políticos venezolanos: cambio de rumbo en la socialización politica venezolana. Ponencia presentada en el VIII Simposio de la Ciencia Política en Venezuela. Centro de Conferencias IDEAS, Sartenejas, Caracas, 21 al 23 de julio.

- (1998c): "La democracia mínima de los venezolanos". Politeia, 21, 45-62.

- (1996): "La lealtad democrática de los venezolanos en los críticos años 90". Cuadernos del CENDES, 33, 91103.

- (1995): "La democracia en la conciencia política del venezolano". Politeia, 18, 43-55.

POPPER, K. (1995): La responsabilidad de vivir. Barcelona: Edic. Paidós.

RAMOS JimENEZ, A. (1997): Las formas modernas de la politica. Estudio sobre la democratización de América Latina. Mérida, Venezuela: Centro de Investigaciones de Politica Comparada, Universidad de los Andes.

REY, J. C. (1991): "La democracia venezolana y la crisis del sistema populista de conciliación". Revista de Estudios Políticos, 74, 533-578.
- (1988): "La democracia, desarrollo y redistribución en Venezuela”. Pensamiento Iberoamericano, 14.

Rivas Quintero, A. (1994): "Democracia representativa y participación popular”. En: COPRE: Una Constitución para el ciudadano. Caracas: Editorial Texto. Pp. 141159.

RIVERO LOZADA, V. (1994): "Notas sobre la discusión de la Reforma Constitucional”. En: COPRE: Una Constitución para el ciudadano. Caracas: Editorial Texto. Pp. 499 529.

SAlAmANCA, L. (1997): Crisis de la modernización y crisis de la democracia en Venezuela. Caracas: U.C.V.-I.L.D.I.S.

SARTORI, G. (1988): Teoría de la democracia. 2. Los problemas clásicos. Argentina: Ediciones Rei.

TORRES, A. (1991): "La evolución de las actitudes hacia el sistema político en Venezuela”. En: COPRE: Venezuela, Democracia y Futuro. Caracas. Pp.173-186.

- (1982): "Familia, fiesta electoral y voto: Un análisis del origen de las lealtades partidistas en Venezuela". Revista de Estudios Políticos, 1, 19-46.

- (1980a): "La "experiencia" política en una democracia partidista joven. El caso de Venezuela”. Politeia, 9, 263 285.

- (1980b): "Crisis o consolidación de los partidos en Venezuela”. Argos, 1, 9-21

- (1978): “¿Son los copeyanos distintos a los adecos?”. Autentico, 66, Caracas, 11de Sept. Pp. 27-29.

Vaivads, H. (1994): "Las elecciones de 1993 y sus efectos sobre los partidos políticos y el sistema de partidos". Cuestiones Politicas, 13, 91-103.

Villarroel, G. (1996): "Democracia sin consenso: Los valores confrontados de la cultura política venezolana". Espacio Abierto. Vol. 5: 223-248.

Welsch, F. y CARRASQUeRo, J. V. (1996): “¿Desconsolidación de la democracia en Venezuela?. Rendimiento y legitimidad normativa". Cuestiones Políticas, 16, 45-69.

Wegener, B. (1996): "Teorías e Ideologías de la justicia”. En: VV. AA.: Perspectivas Teóricas y Comparadas de la Igualdad. Madrid: Fundación Argentaria y Visor, S.A. Pp. 169-188.

ZAPATA, R. (1995): Los valores del venezolano. Caracas: Conciencia 21. 


\section{RESUMEN}

A objeto de establecer los rasgos principales de las actitudes políticas en Venezuela, el presente trabajo examina la consistencia de las lealtades partidistas, el estilo de democracia prevaleciente e indaga en las divisiones ideológicas y sociales respecto de la desigualdad social, haciendo uso del método estadístico para el análisis de encuestas y la comparaçión de datos provenientes de encuestas hechas en 1973, 1983, 1993 y 1995 con fines de investigación científica. Se concluye que la transferencia partidista en el proceso de socialización política se ha debilitado, pero permanece alta la adhesión democrática dentro de una concepción procedimental de la misma y las diferencias sociales e ideológicas respecto de la igualdad social se están produciendo, todo lo cual modifica el consenso que propició la regularidad democrática entre 1968 y 1988 y presagia cambios significativos en el sistema político que sugieren el seguimiento analítico en lo sucesivo de las actitudes políticas para establecer las tendencias.

Palabras clave: Actitudes políticas, cultura política, comportamiento político.

\section{ABSTRACT}

To determine the main features of the political attitudes in Venezuela, this article examines the consistency of party loyalties, the prevailing style of democracy and the social and ideological divergences regarding social inequality, by means of the statistical analysis of surveys and the comparison of survey data collected in 1973, 1983,1993 and 1995.

The conclusion is that the party transference in the process of political socialization has weakened, whereas the democratic adherence under a procedural conception of democracy remains high. Social and political divergences regarding social inequality are also present, all together modifying the consensus that promoted the democratic order between 1968 and 1988 and foreseeing significant changes in the political system which advise to follow analytically the evolution of the political attitudes and establish their trends.

Key words: Political attitudes, political culture, political behavior.

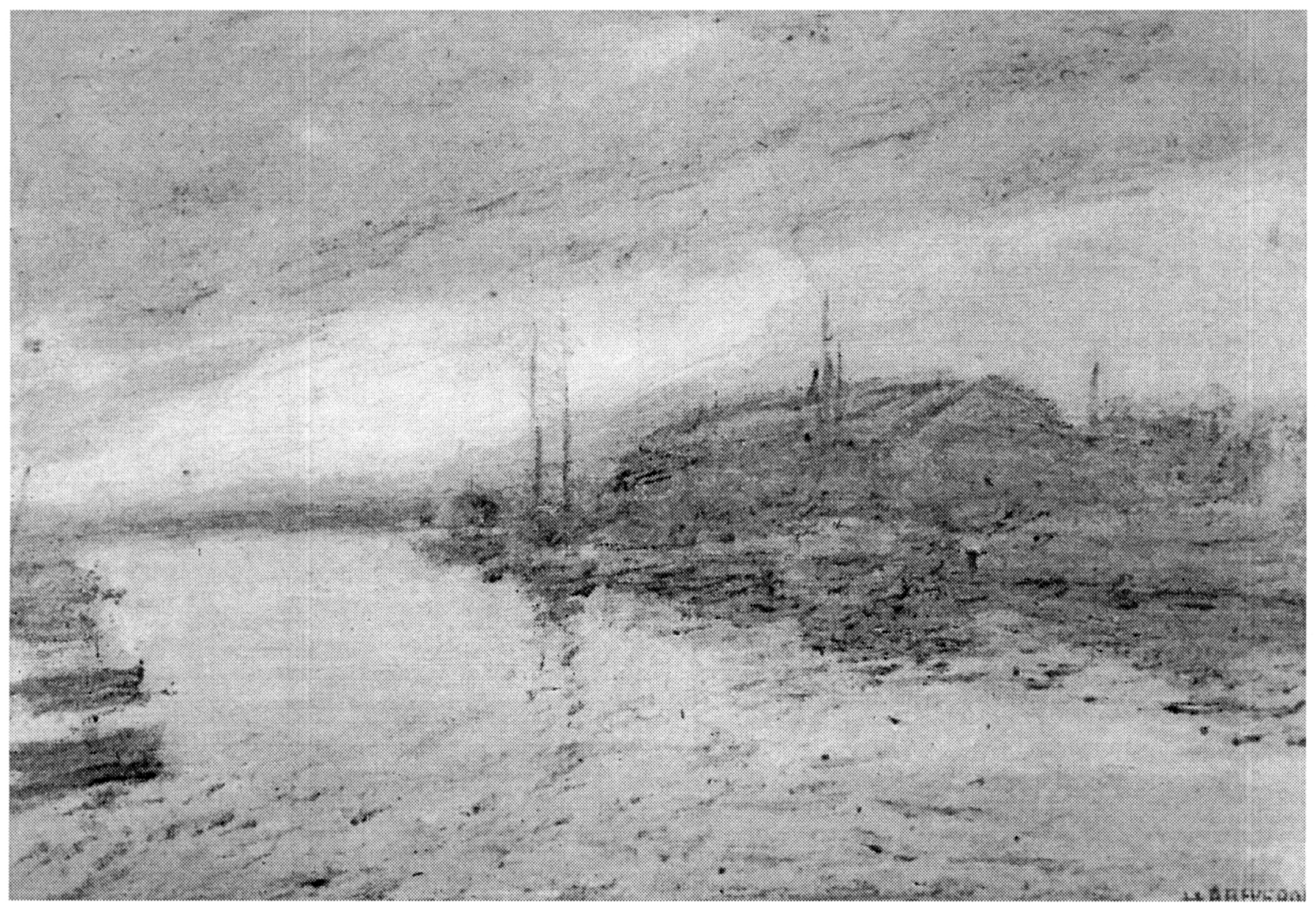

"Puerto de la Guaira”, Armando Reverán 